\title{
Impact of premenstrual syndrome on multiple sclerosis symptoms in adult female: a retrospective cross-sectional study
}

\author{
Yosra Elhussein IBRAHIM ${ }^{1}$, Soheir Mahmoud ELKOSERY ${ }^{2}$, Mohamed Fawzy ABO ELAININ ${ }^{3}$, Afaf \\ Mohamed Mahmoud BOTLA ${ }^{4}$ \\ ${ }^{1}$ BSC in Physical Therapy Cairo University, Egypt \\ ${ }^{2}$ Professor and Chairman of Physical Therapy Department for Woman's Health Faculty of Physical Therapy Cairo University, Egypt \\ ${ }^{3}$ Consultant and Chairman of Department of Obstetrics and Gynecology Om El-Masryeen Hospital, Egypt \\ ${ }^{4}$ Assistant Prof. of Physical Therapy for Woman's Health Faculty of Physical Therapy Cairo University, Egypt \\ Corresponding author's Email: drafafmohamed@yahoo.com; (D) ORCID: 0000-0002-6426-6997
}

\section{ABSTRACT}

Introduction. Premenstrual syndrome (PMS) is a group of symptoms that many women get about a week or two before their period. Multiple sclerosis (MS) is an autoimmune-mediated disorder that affects the central nervous system (CNS). Aim. This study aimed to see the impact of premenstrual syndrome on multiple sclerosis symptoms. Methods. Forty women having MS and complained from PMS, aged 20-35 years, with BMI less than $30 \mathrm{~kg} / \mathrm{m}^{2}$ were selected randomly from Health Insurance Authority in El-Dokki they were assessed during two periods (normal and premenstrual days). The MS symptoms was assessed through functional system scale; fatigue severity scale and numerical scale and also premenstrual symptoms are assessed by PMS tracker. Results. Multiple pairwise comparison tests revealed that there was significant increase in functional system score in premenstrual period ( $p=0.006)$, and also in fatigue severity scale in pre-menstrual period $(p=0.0001)$. Numerical rating scale showed that there was significant increase in pain intensity $(p=0.0001)$ which became more prominent in pre-menstrual period. Conclusion. Premenstrual syndrome has an effect on worsening the symptoms of multiple sclerosis.

\section{Research Article}

PII: S225199392100013-11

Rec. 17 July 2021

Rev. 15 November 2021

Acc. 20 November 2021

\section{Keywords}

Premenstrual syndrome, Multiple sclerosis,

Functional system scale, Fatigue severity scale.

\section{INTRODUCTION}

At extreme period of reproductive system as at menarche and menopause the menstrual cycle doesn't become regular due to occurrence of anovulation and improper follicular development, although luteal phase in all female is the same. The difference that happens between females in length of the menstrual cycle is due to the difference of the follicular phase that can range from 10 to 16 days [1].

Most women about $80 \%$ of women suffer from breast tenderness, mood swings, acne, bloating and feeling tired about one to two weeks before menstruation. Most of these symptoms interfere with daily life activities in about 20 to $30 \%$ of all women having PMS. Premenstrual syndrome (PMS) is a group of symptoms about $90 \%$ of women suffer from as breast tenderness, bloating and moodiness where these symptoms occur from one to two weeks before menstruation [2]. PMS severity differs from woman to another where there are women where their symptoms become so severe that they miss their work or school, others don't bother themselves with their symptoms. It is more widespread in 30 s women to have PMS [3].

Multiple sclerosis (MS) is autoimmune disease; it is a demyelinating disease where myeline sheath around nerve cells in brain and spinal cord is being damaged. The result of the damage that happen to nerve cells that it doesn't make the nerve cell able to work probably thus resulting in specific symptoms as double vision, muscle weakness, trouble with sensation also with coordination and blindness [4]. Multiple sclerosis occurs in many forms first can be relapsing-remitting form where new symptoms occur as attack called a relapse and then these symptoms disappear after a while, secondly could be as building up symptoms where the symptoms progress and increase disability called secondary progressive where permanent disease advance occur [5].

some studies show that women with MS who have been pregnant have less progression of disability [6] During pregnancy women with MS are in immune suppressant state where rate of getting a relapse is significantly decreased due to increased level of estrogen then very soon after delivery the risk of getting a 
relapse increased due to sudden decreased in estrogen levels after delivery. So this is a significant evidence that estrogen, progesterone and testosterone has a great role in controlling MS activity as they influence immune response and contribute in repairing mechanism in nervous system fluctuations in medical and health conditions happens at specific phases of menstrual cycle especially at luteal phase and menstrual phases [7].

This study was conducted to determine whether premenstrual syndrome affect multiple sclerosis symptoms or not.

\section{MATERIALS AND METHODS}

\section{Ethical approval}

The research related to human use has been completed with all relevant national regulations and institutional policies, has been approved by research ethics committee of faculty of physical therapy, Cairo University (No: P.T.REC/O12/003248).

\section{Study Design}

The study was designed as retrospective. It was conducted at Health Insurance Authority in El Dokki. It was conducted between September 2020 and March 2021.

\section{Participants}

Forty women with multiple sclerosis were selected randomly from Health Insurance Authority in El-Dokki to participate in this study. To be included in the study, the participants were chosen having PMS syndrome based on tracking their symptoms at least previous 2 menstrual cycle using premenstrual syndrome tracker, having a relapse of MS at least once per year. Their ages ranged from 20 to 35 years old, their BMI was less than $30 \mathrm{~kg} / \mathrm{m}^{2}$. The participants were excluded if their BMI exceed $30 \mathrm{~kg} / \mathrm{m}^{2}$, smoking women, if they had any uterine problems or complain other than PMS.

\section{Procedures}

All patients were given a full explanation of the protocol of the study and consent form was signed for each patient before participating in the study.

- Tracking of PMS days: The premenstrual syndrome tracker sheet was given to the patient to mark and write the symptoms she feels on each day from day 1 to end of the menstrual cycle to assess the beginning of premenstrual syndrome days.

- Assessment of the MS symptoms: The symptoms of MS were assessed during premenstrual period (10 days before menstruation) as well as during normal days (rest of month after end of menstruation), using expanded disability scale (functional systems scale) and fatigue severity scale as well as numerical rating scale.

- Expanded disability status scale (EDSS): EDSS scale is used mainly to measure the ambulatory state of multiple sclerosis patient, the scoring takes 30 minutes to make a score.

- The functional system scale is used to measure the wellness of major central nervous system: Functional system scale includes: pyramidal functions, cerebellar functions, cortical functions, bladder functions, with the help of functional system scale, involuntary movements, loss of coordination, mental function. The examiner can rate the disability on EDSS scale. The scores ranged from o to 10. Less sever disability show low numbers, and vice versa: Amato and Ponziani [8] named it (good validity) also Ebers et al. [9] certified validity as "well validated".

- Fatigue severity scale: $80 \%$ of multiple sclerosis patient suffer from fatigue which is considered the most common symptom which interfere with daily life activities including work [10, 11]; The fatigue severity scale is a scale used to measure the severity of fatigue and its effect on any person Daily life activities, it is mainly designed for multiple sclerosis patients [12]. The fatigue severity scale is a 9-item scale, it is a statement given to patient it includes 9 items; The patient read each statement and mark a number from 1 to 7 where 1 means strongly disagree, 9 means strongly agree; The higher score, the more severe the fatigue is and affects the person daily life activities. The scale is valid and conducted in English [13, 14] also in Arabic [15].

- Numerical rating scale: Chronic pain is a common symptom in multiple sclerosis, where pain is felt in different sites $[16,17]$. There is a significant difference in experience of pain where it could be felt for a short period of time in some sites or could be persistent as in neuropathic or musculoskeletal origin. Pain is usually measured by numerical rating scale in many medical cases; The numerical rating scale (NRS) where pain intensity is rated from 0 to 10, where o means no pain and 10 means sever pain [18]. NRS is too easy to be demonstrated to the patient to understand and of good sensitivity and clinical relevance [19]. 


\section{Statistical analysis}

Statistical analysis was conducted using SPSS for windows, version 23 (SPSS, Inc., Chicago, IL). The current test involved one independent variable was the (measuring periods); within subject factor which had two levels (normal period and pre-menstrual period). In addition, this test involved three tested dependent variables (Functional system score, fatigue severity scale and numeric rating scale). Before final analysis, data were screened for normality assumption, homogeneity of variance, and presence of extreme scores. This exploration was done as a pre-requisite for parametric calculations of the analysis of difference. Descriptive analysis using histograms with the normal distribution curve showed that the functional system score, fatigue severity scale and numeric rating scale were normally distributed and not violates the parametric assumption for the measured dependent variable. The box and whiskers plots of the tested variable were done to detect outliers and showed no outliers. Normality test of data using Shapiro-Wilk test was used, that reflect the data was normally distributed for functional system score, fatigue severity scale and numeric rating scale. Accordingly, Repeated Measure MANOVA was used to compare the functional system score, fatigue severity scale and numeric rating scale at different measuring periods. The alpha level was set at 0.05 .

\section{RESULTS}

The results showed that there were significant effects of the tested measuring periods (the independent variable) on the three tested dependent variables; (functional system score, fatigue severity scale and numeric rating scale) $\left(\mathrm{F}=61.945, \mathrm{P}=0.001^{*}\right)$ as illustrated at tables 1-3. PMS tracker was given to patients to conduct the timing premenstrual days it was conducted between women 70\% began their symptoms 5 days before the menstruation took place while $30 \%$ their PMS symptoms started to show from 10 to 8 days before menstruation

Table 1. Descriptive statistics and repeated measure MANOVA for the Expanded disability status scale with Functional System Score) at both periods

\begin{tabular}{lcc} 
Mean \pm SD & Normal period & Pre-menstrual period \\
Functional System Score & $3.52 \pm 1.71$ & $3.78 \pm 1.58$ \\
\hline \multicolumn{3}{l}{ The univariate tests for the mean of the Functional System Score at both Periods } \\
\hline & F-value & P-value \\
\hline Functional System Score & 8.895 & $0.0006^{*}$ \\
\hline Multiple pairwise comparison tests (Post hoc tests) for the Functional System Score at both Periods \\
\hline Functional System Score & Normal period Versus Pre-menstrual period \\
\hline P-value & $0.006^{*}$ \\
\hline
\end{tabular}

Table 2. Descriptive statistics and repeated measure MANOVA for the Fatigue severity scale at both periods

\begin{tabular}{|c|c|c|}
\hline Mean \pm SD & Normal period & Pre-menstrual period \\
\hline Fatigue severity scale & $3.46 \pm 1.62$ & $4.46 \pm 1.71$ \\
\hline \multicolumn{3}{|c|}{ The univariate tests for the mean of the Fatigue severity scale at both Periods } \\
\hline & F-value & P-value \\
\hline Fatigue severity scale & 73.444 & $0.0001^{*}$ \\
\hline \multicolumn{3}{|c|}{ Multiple pairwise comparison tests (Post hoc tests) for the Fatigue severity scale at both Periods } \\
\hline Fatigue severity scale & \multicolumn{2}{|c|}{ Normal period Versus Pre-menstrual period } \\
\hline P-value & \multicolumn{2}{|c|}{$0.0001^{*}$} \\
\hline
\end{tabular}

Table 3. Descriptive statistics and repeated measure MANOVA for the Numeric rating scale at both periods

\begin{tabular}{|c|c|c|}
\hline Mean \pm SD & Normal period & Pre-menstrual period \\
\hline Numeric rating scale & $3.88 \pm 1.85$ & $7.36 \pm 2.09$ \\
\hline \multicolumn{3}{|c|}{ The univariate tests for the mean of the Numeric rating scale at both Periods } \\
\hline & F-value & P-value \\
\hline Numeric rating scale & 95.307 & $0.0001^{*}$ \\
\hline \multicolumn{3}{|c|}{ Multiple pairwise comparison tests (Post hoc tests) for the Numeric rating scale at both Periods } \\
\hline Numeric rating scale & \multicolumn{2}{|c|}{ Normal period Versus Pre-menstrual period } \\
\hline P-value & \multicolumn{2}{|c|}{$0.0001^{*}$} \\
\hline
\end{tabular}


Menstrual cycle is a normal change that happen every month in female reproductive system to make pregnancy occur. Many women suffer from behavioral symptoms such as fatigue, insomnia, over eating and dizziness; physical symptoms such as bloating, moodiness, breast tenderness and headache and also psychological symptoms such as depression, mood changes, anxiety and anger, from one to 2 weeks before menstruation. These symptoms are defined as premenstrual syndrome (PMS). In some women symptoms are mild that they don't bother themselves with the symptoms, others are so severe they skip work, school [20].

Menstrual cycle of women consists of 3 levels according to estrogen, progesterone levels. First 3 days after menstruation took place till ovulation is called ist level where elevated estrogen level took place. Second level was from ovulation (about 14 days in 28 days of menstrual cycle) to 5 days before next menstrual cycle where elevated levels of estrogen and progesterone. Last level is about 5 days before next menstrual cycle where levels of estrogen and progesterone are decreased [21]. Multiple sclerosis is autoimmune demyelinating disease, where demyelination of nerve axons in central nervous system takes place. The incidence of MS is in adolscenece and adult it is more in women 3 times than men [22].

Estrone (E1), estriol (E3 produced at pregnancy only) and 17 $\beta$-estradiol (E2) are endogenous estrogens which are produced in female mammals. E2 is predominant form in pre-menopausal women. There are two forms of estrogen receptors (ERs): ER $\alpha$ (NR3Al) and ER $\beta$ (NR3A2). These receptors act as ligand-activated transcription factors, thus they directly regulate a broad range of estrogen-responsive genes present in all cells of the innate and adaptive immune system. Also, progesterone has w pregestational effect for which it belongs to progesterone steroid family in which progesterone receptor (PR) whom is a part of nuclear hormone receptor super family of transcription factors mediate it. PRs are found in many immune cells as dendritic cells, $\mathrm{T}$ cells, granulocytes, NK cells and B cells [23]. Ovarian sex steroids has immune response in which it could change any immune disorder from pro-inflammatory in to anti-inflammatory, especially favoring Treg cell differentiation and promoting down-regulation of IFN- $\gamma$ production by NK cells, and glucocorticoid-mediated thymocyte apoptosis [24].

Therefore, the current study aimed to study the impact of premenstrual syndrome on multiple sclerosis symptoms. The study was carried on forty multiple sclerosis women suffering from premenstrual syndrome who were randomly chosen. Evaluation was carried in two periods, premenstrual period (10 to 8 days before menstruation) and normal period (rest of month after end of menstruation) through functional system scoring, fatigue severity scale and numeric rating scale.

The result showed that there was a significance increase in functional system score, fatigue severity scale and numeric rating scale of premenstrual period compared with those of normal days with $(\mathrm{F}=8.895, \mathrm{P}=0.0006)$, ( $\mathrm{F}=73.444, \mathrm{P}=0.0001)$ and $(\mathrm{F}=95.307, \mathrm{P}=0.0001$ ) respectively.

These results of worsening MS symptoms at premenstrual period can be explained by the withdrawal of estrogen at the premenstrual phase. As the estrogen has an immunomodulatory effect that includes 1) its effect on multiple components of the immune response; 2 ) its various effects on different systems in which it appears pro-autoimmune, as in murine lupus and anti-inflammatory; 3) its effect on other hormones which are potentially modulate the immunity [25].

A role for autoimmunity in the etiology of MS is suggested by its similarity to the immunologically mediated animal model experimental allergic encephalomyelitis, and by the finding of reduced levels of circulating suppressor $\mathrm{T}$ cells accompanying relapse.

The result of the current study come in agreement with reports of Yarraelit and Correale [25] as they concluded that the estrogen has an effect on central monoamine neurotransmission where low levels of estrogen in women are associated with postnatal depression, post-menopausal depression and premenstrual syndrome. And also Yarraelit and Correale [25] concluded that autoimmunity disorder could be modulated by the influence of estrogen.

Also our result run in the same line with those of Etemadifar et al. [26] as they found that $50.6 \%$ of attacks occurs where low levels of estrogen and progesterone happen at premenstrual phase while $27 \%$ of attacks occurs at follicular phase where estrogen, levels are increased, as well as $22.4 \%$ of attacks occurred at ovulatory phase where estrogen progesterone levels are highest. There is a strong relation and effect of estrogen on the course of MS symptoms, where during pregnancy women with MS are in immune suppressant state because During pregnancy, influences from the placenta, the mother and the fetus condition placentation, regulating placental growth predisposing regulation of a Th2-like anti-inflammatory immune response. During this

Ibrahim YE, Elkosery SM, Abo Elainin MF, and Botla AMM. Impact of premenstrual syndrome on multiple sclerosis symptoms in adult female: a retrospective cross-sectional study. J Life Sci Biomed, 2021; 11(6): 107-112. DOI: https://dx.doi.org/10.51145/jlsb.2021.13 
period, it is possible to observe a marked increase in the levels of estrogens, progesterone, glucocorticoids, and activated vitamin $\mathrm{D}$ coming from both the mother and the placenta. Taken together, these factors decrease maternal cellular immunity, evidenced by decreased number of multiple sclerosis exacerbations during pregnancy, particularly during the third trimester. B, B cells; DHEA, dehydroepiandrosterone; GM-CSF, granulocyte-macrophage colony-stimulating factor; IFN, interferon; LGL, large granular lymphocytes; M-CSF, macrophage colony-stimulating factor; MS, multiple sclerosis; $\mathrm{M} \Phi$, macrophages; NK, NK cells; $\mathrm{T}$, $\mathrm{T}$ cells.

Where rate of getting a relapse is significantly decreased due to increased level of estrogen then very soon after delivery the risk of getting a relapse increased due to sudden decreased in estrogen levels after delivery. So, this is significant evidence that estrogen, progesterone and testosterone have a great role in controlling MS activity as they influence immune response and contribute in repairing mechanism in nervous system [27].

In disagreement of our study, Zakrzewska-Pniewska et al. [28] concluded that during premenstrual phase the abnormal hormonal patterns occur correlated with intensity of MRI changes ( $p<0.05$, Fisher's exact test), but there was no hypothalamic or MS changes (Expanded Disability Status Scale, relapse rate, disease duration).

\section{CONCLUSION}

Premenstrual syndrome has an effect on multiple sclerosis as it worse the symptoms.

\section{DECLARATIONS}

\section{Authors' contributions}

All authors contributed equally to this work.

\section{Acknowledgment}

The authors would like to thank all individuals who contribute to the completion of this work, especially MS women who participate in this study.

\section{Conflict of interest}

The authors have no conflict of interest.

\section{Source of funding}

This study received no financial support.

\section{REFERENCES}

1) Vellacott ID, Shroff NE, Pearce MY, Stratford ME, Akbar FA. A double-blind, placebo-controlled evaluation of spironolactone in the premenstrual syndrome. Current medical research and opinion. 1987 Jan $1_{i}$ 10(7):450-6. DOI: https://doi.org/10.1185/03007998709112403

2) Freeman EW, Rickels K, Sondheimer SJ, Polansky M. A double-blind trial of oral progesterone, alprazolam, and placebo in treatment of severe premenstrual syndrome. Jama. 1995 Jul 5; 274(1):51-7.

3) Labots-Vogelesang MS, Teunissen DA, Kranenburg V, Lagro-Janssen AL. Views of Dutch general practitioners about premenstrual symptoms: A qualitative interview study. European Journal of General Practice. 2021 Jan 1; 27(1):19-26. DOI: https://doi.org/10.1080/13814788.2021.1889505

4) Compston A, Coles A. Multiple sclerosis. 2002, Lancet. 359 (9313): 1221-31. DOI: https://doi.org/10.1016/So140-6736(02)08220-X

5) Lublin FD, Reingold SC. Defining the clinical course of multiple sclerosis: results of an international survey. Neurology. 1996 Apr 1 ; 46(4):907-11. DOI: https://doi.org/10.1212/WNL.46.4.907

6) D'hooghe MB, Nagels G. Long-term effects of childbirth in MS. Journal of Neurology, Neurosurgery \& Psychiatry. 2010 Jan 1; 81(1):3841. DOI: http://dx.doi.org/10.1136/jnnp.2008.163816

7) Case AM, Reid RL. Menstrual cycle effects on common medical conditions. Comprehensive therapy. 2001 Mar; 27(1):65-71. DOI: https://doi.org/10.1007/s12019-001-0010-8

8) Amato MP, Ponziani G. Quantification of impairment in MS: discussion of the scales in use. Multiple Sclerosis Journal. 1999 Aug; 5(4):216-9. DOI: https://doi.org/10.1177/135245859900500404

9) Ebers GC, Heigenhauser L, Daumer M, Lederer C, Noseworthy JH. Disability as an outcome in MS clinical trials. Neurology. 2008 Aug 26; 71(9):624-31. DOI: https://doi.org/10.1212/01.wnl.0000313034.46883.16

10) Lerdal A, Gulowsen Celius E, Krupp L, Dahl AA. A prospective study of patterns of fatigue in multiple sclerosis. European Journal of Neurology. 2007 Dec; 14(12):1338-43. DOI: https://doi.org/10.1111/j.1468-1331.2007.01974.x

11) Shah A. Fatigue in multiple sclerosis. Physical medicine and rehabilitation clinics of North America. 2009 May 1; $20(2): 363-72$. https://bmjopen.bmj.com/content/8/1/eo16297.abstract DOI: https://doi.org/10.1016/j.pmr.2008.12.003 
12) Krupp LB, LaRocca NG, Muir-Nash J, Steinberg AD. The fatigue severity scale: application to patients with multiple sclerosis and systemic lupus erythematosus. Archives of neurology. 1989 Oct $1 ; \quad 46(10): 1121-3 . \quad$ DOI: https://doi.org/10.1001/archneur.1989.00520460115022 ; Direct link

13) Weiland TJ, Jelinek GA, Marck CH, Hadgkiss EJ, van der Meer DM, Pereira NG, Taylor KL. Clinically significant fatigue: prevalence and associated factors in an international sample of adults with multiple sclerosis recruited via the internet. PLoS One. 2015 Feb 18; 10(2):e0115541. DOI: https://doi.org/10.1371/journal.pone.0115541

14) Amtmann D, Bamer AM, Noonan V, Lang N, Kim J, Cook KF. Comparison of the psychometric properties of two fatigue scales in multiple sclerosis. Rehabilitation psychology. 2012 May; 57(2):159. DOI: https://doi.org/10.1037/a0027890

15) Al-Sobayel HI, Al-Hugail HA, AlSaif RM, Albawardi NM, Alnahdi AH, Daif AM, Al-Arfaj HF. Validation of an Arabic version of fatigue severity scale. Saudi medical journal. 2016 Jan; 37(1):73. https://www.ncbi.nlm.nih.gov/pmc/articles/PMC4724683/

16) Ehde DM, Gibbons LE, Chwastiak L, Bombardier CH, Sullivan MD, Kraft GH. Chronic pain in a large community sample of persons with multiple sclerosis. Multiple Sclerosis Journal. 2003 Dec; 9(6):605-11. DOI: https://doi.org/10.1191/1352458503ms9390a

17) Archibald CJ, McGrath PJ, Ritvo PG, Fisk JD, Bhan V, Maxner CE, Murray TJ. Pain prevalence, severity and impact in a clinic sample of multiple sclerosis patients. Pain. $1994 \mathrm{Jul}$ 1; 58(1):89-93. https://doi.org/10.1016/0304-3959(94)90188-0

18) Jensen MP, Turner JA, Romano JM, Fisher LD. Comparative reliability and validity of chronic pain intensity measures. Pain. 1999 Nov 1; 83(2):157-62. DOI: https://doi.org/10.1016/S0304-3959(99)00101-3

19) Underwood J, Clark PC, Blanton S, Aycock DM, Wolf SL. Pain, fatigue, and intensity of practice in people with stroke who are receiving constraint-induced movement therapy. Physical therapy. 2006 Sep 1;86(9):1241-50. DOI: https://doi.org/10.2522/ptj.20050357

20) Wyatt K, Dimmock PW, O'Brien PM. Premenstrual syndrome. In: Barton S, ed. Clinical evidence. 4th issue. London: 20oo BMJ Publishing Group. 1121-33. https://www.sciencedirect.com/science/article/abs/pii/So140673608605279

21) Khan D, Ansar Ahmed S. The immune system is a natural target for estrogen action: opposing effects of estrogen in two prototypical autoimmune diseases. Frontiers in immunology. 2016 Jan 6; 6:635. DOI: https://doi.org/10.3389/fimmu.2015.00635

22) Koch-Henriksen N, Sørensen PS. The changing demographic pattern of multiple sclerosis epidemiology. The Lancet Neurology. 2010 May 1; 9(5):520-32. DOI: https://doi.org/10.1016/S1474-4422(10)70064-8

23) Cui J, Shen Y, Li R. Estrogen synthesis and signaling pathways during aging: from periphery to brain. Trends in molecular medicine. 2013 Mar 1; 19(3):197-209. DOI: https://doi.org/10.1016/j.molmed.2012.12.007

24) Enninga EA, Nevala WK, Creedon DJ, Markovic SN, Holtan SG. Fetal sex-based differences in maternal hormones, angiogenic factors, and immune mediators during pregnancy and the postpartum period. American journal of reproductive immunology. 2015 Mar; 73(3):251-62. DOI: https://doi.org/10.1111/aji.12303

25) Ysrraelit MC, Correale J. Impact of sex hormones on immune function and multiple sclerosis development. Immunology. 2019 Jan; 156(1):9-22. DOI: https://doi.org/10.1111/imm.13004

26) Etemadifar M, Chitsaz A, Tehrani HG, Harati M. Assessing the Impact of Menstrual Cycle in Incidence of Symptoms of Patients with Multiple Sclerosis Referring to Alzahra Hospital, Isfahan, Iran. Journal of Isfahan Medical School. 2011 Dec 19;29(159). Google Scholar

27) D'hooghe MB, Nagels G. Long-term effects of childbirth in MS. Journal of Neurology, Neurosurgery \& Psychiatry. 2010 Jan 1; 81(1):3841. DOI: http://dx.doi.org/10.1136/jnnp.2008.163816

28) Zakrzewska-Pniewska B, Gołębiowski M, Zajda M, Szeszkowski W, Podlecka-Piętowska A, Nojszewska M. Sex hormone patterns in women with multiple sclerosis as related to disease activity-A pilot study. Neurologia i neurochirurgia polska. 2011; 45(6):536-42. DOI: https://doi.org/10.1016/S0028-3843(14)60120-1 